\title{
The Influence Catalyst Layer Thickness on Resistance Contributions of PEMFC Determined by Electrochemical Impedance Spectroscopy
}

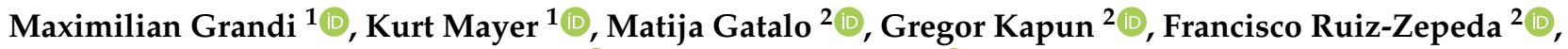 \\ Bernhard Marius $^{1}$, Miran Gaberšček ${ }^{2}$ iD and Viktor Hacker ${ }^{1, * \mathbb{D}}$ \\ 1 Institute of Chemical Engineering and Environmental Technology, Graz University of Technology, \\ Inffeldgasse 25/C, 8010 Graz, Austria; maximilian.grandi@tugraz.at (M.G.); kurt.mayer@tugraz.at (K.M.); \\ b.marius@tugraz.at (B.M.) \\ 2 Department of Materials Chemistry, National Institute of Chemistry, Hajdrihova 19, 1001 Ljubljana, Slovenia; \\ matija.gatalo@ki.si (M.G.); Gregor.Kapun@ki.si (G.K.); Francisco.RuizZepeda@ki.si (F.R.-Z.); \\ miran.gaberscek@ki.si (M.G.) \\ * Correspondence: viktor.hacker@tugraz.at
}

check for updates

Citation: Grandi, M.; Mayer, K.; Gatalo, M.; Kapun, G.; Ruiz-Zepeda, F.; Marius, B.; Gaberšček, M.; Hacker, V. The Influence Catalyst Layer Thickness on Resistance Contributions of PEMFC Determined by Electrochemical Impedance Spectroscopy. Energies 2021, 14, 7299. https://doi.org/10.3390/en14217299

Academic Editor: Felix Barreras

Received: 2 September 2021

Accepted: 25 October 2021

Published: 4 November 2021

Publisher's Note: MDPI stays neutral with regard to jurisdictional claims in published maps and institutional affiliations.

Copyright: (c) 2021 by the authors. Licensee MDPI, Basel, Switzerland. This article is an open access article distributed under the terms and conditions of the Creative Commons Attribution (CC BY) license (https:/ / creativecommons.org/licenses/by/ $4.0 /)$.

\begin{abstract}
Electrochemical impedance spectroscopy is an important tool for fuel-cell analysis and monitoring. This study focuses on the low-AC frequencies $(2-0.1 \mathrm{~Hz})$ to show that the thickness of the catalyst layer significantly influences the overall resistance of the cell. By combining known models, a new equivalent circuit model was generated. The new model is able to simulate the impedance signal in the complete frequency spectrum of $10^{5}-10^{-2} \mathrm{~Hz}$, usually used in experimental work on polymer electrolyte fuel cells (PEMFCs). The model was compared with experimental data and to an older model from the literature for verification. The electrochemical impedance spectra recorded on different MEAs with cathode catalyst layer thicknesses of approx. 5 and $12 \mu \mathrm{m}$ show the appearance of a third semicircle in the low-frequency region that scales with current density. It has been shown that the ohmic resistance contribution $\left(\mathrm{R}_{\mathrm{mt}}\right)$ of this third semicircle increases with the catalyst layer's thickness. Furthermore, the electrolyte resistance is shown to decrease with increasing catalyst-layer thickness. The cause of this phenomenon was identified to be increased water retention by thicker catalyst layers.
\end{abstract}

Keywords: PEMFC; electrochemical impedance spectroscopy; equivalent circuit modelling; electrode design

\section{Introduction}

The development and optimization of the key components of proton exchange membrane fuel cells (PEMFCs) are necessary for the material cost reduction needed for the adoption of PEMFC technology in everyday life [1-4]. One such key components to be optimized is the catalyst layer of the MEA. To tackle this task, the identification of crucial electrode parameters and their influence on the voltage loss is necessary.

Electrochemical impedance spectroscopy (EIS) is a very powerful method to investigate the contributions of individual effects on overall fuel cell performance in laboratory research and system development. The interpretation of the obtained data is, however, rather challenging and can potentially lead to false conclusions. Adding to the difficulty is the multitude of different models presented in literature that often leave researchers puzzled as to their choices for interpreting their data. This is especially true for the description of low-frequency features in the range of 2 to $0.01 \mathrm{~Hz}$, where diffusion-related impedance signals appear [5-8]. The higher spectrum within this range $(2-0.2 \mathrm{~Hz})$ often produces a third semicircle in the negative impedance plane, defined as a negative low frequency impedance (NLFI) [7-11]. The lower spectrum of this frequency range $(0.2-0.01)$ produces 
a semicircle in the positive impedance plane [5,12-14], defined as positive low-frequency impedance (PLFI) for easier distinction from NLFI.

PLFI has been interpreted as having stemmed from various different effects, namely [5,12]:

(i) Side reactions with intermediate species on the catalyst surface; for PEMFC, the oxidation of adsorbed intermediates $\left(\mathrm{O}_{\mathrm{ads}}, \mathrm{OH}_{\mathrm{ads}}\right.$ or $\left.\mathrm{O}_{2} \mathrm{H}_{\mathrm{ads}}\right)$.

(ii) Water transport phenomena in the catalyst layer.

(iii) Poisoning of the catalyst layer with carbon monoxide.

(iv) Changing temperatures, through joule heating, from the excitation current.

Based on the provided examples it can be understood that the interpretations of the EIS data varies greatly, depending on the nature of the underlying phenomena behind it. The most probable cause, from a mechanistic point of view, for the oxygen reduction reaction is an adsorption step or the formation of $\mathrm{PtO}[5,15]$.

Since both the NLFI and PLFI loops are directly adjacent to each other, they can influence the results of an impedance analysis if one is not considered.

Some of the initial studies on equivalent circuit models for PEMFC were performed approximately twenty-five years ago. These were mostly based on planar electrodes, consisting of a resistor and a capacitor, in parallel, for each electrode, and a resistor, in series, for the electrolyte and current collector resistances [16]. If the time constants of the two electrodes are far enough apart, the two electrodes can be distinguished in the impedance spectrum of normal $\mathrm{H}_{2} / \mathrm{O}_{2}$ operation $[16,17]$. One way to determine this is by recording impedance spectra in a half cell setup or using a reference electrode in situ $[18,19]$. However, the position of the reference electrode largely influences the results. It should be positioned in the centre of the electrolyte, close to the electrode, with its dimensions being small compared to electrolyte thickness. During the stages of the first EIS studies in the early 2000s typical membrane thickness was around 100-200 $\mu \mathrm{m}$ and pseudo references had to keep thicknesses of $<20-50 \mu \mathrm{m}[18,20]$. As membranes became thinner over time-reaching already $10 \mu \mathrm{m}$ in some cases [21]—this task became even more challenging. To circumvent this challenge, the time constants of the half-cell reactions can be determined by so-called "symmetric-cell" experiments, where the cell is identical on both electrodes and fed with hydrogen or oxygen on both sides. An impedance spectrum is recorded at OCV to determine the charge transfer of the corresponding electrode. Following these first experiments it was observed that, generally, the charge transfer resistance is much larger for the cathode than for the anode and can, therefore, be distinguished during normal operation [17-20].

The classical equivalent circuit model to describe non-planar electrodes is the transmission line model for porous electrodes [16]. This consists of several RC elements connected to one another by resistances and forming a complex "ladder". Each RC-element represents a volume fraction of the porous electrode. As this model is most certainly the best representation of the electrodes in a PEMFC, it is also very work-intensive to parametrize and needs significant processing power for the used CPU. This means that it is not well-suited for applications in on-board analysis or quick assessments during experimental work in the laboratory.

Certain boundary conditions must be met for the equivalent circuit modelling approach to be correct. Using high stoichiometry and an ensuring even distribution of the double layer capacitance, the simple planar electrode models can be used to analyse data from the impedance spectra [16]. The simple equivalent circuit approach has, therefore, been used in a high number of studies and practical models for system monitoring in fuel-cell technology $[7,8,11,12,22-24]$. In the system monitoring application, EIS is very attractive as it (i) requires only minimal additions in the required hardware and (ii) enables for a significantly faster means of obtaining data in contrast to recording of a complete polarization curve [13]. 
Some of the first attempts to describe diffusion related arcs in the NLFI spectrum were from M. Schulze and N. Wagner in their respective works $[7,11]$. They were among the first to use two RC elements to simulate the two electrodes respectively and to use a third $\mathrm{RC}$ element for the diffusion through the electrodes. Their model has since been reused in a few studies aimed at stack performance and degradation diagnostics $[25,26]$.

As much as these models prove to be simple and practicable in their application, they fail to simulate PLFI features. Such features are being consistently reported by many researchers in their work $[5,12,13]$ and models for their discussion have been proposed. Pivac et al. have used an inductivity in parallel with the charge-transfer resistance of the electrode and capacitance of the electrochemical double layer to reproduce this feature in their simulation [13]. In contrast D. Klotz correctly argues that an inductivity shows high impedance values only at high frequencies and, therefore, a capacitance with negative value must be used for simulating PLFI features [5]. Both however, do not include a third time constant in the negative plain, as in the models by Schulze and Wagner, and, therefore, fail to correctly simulate diffusion-related signals in the NLFI spectrum.

As membrane electrode assembly (MEA) performance strongly influences EIS signals, it is common to use the technique in MEA design studies [4,7,27-30]. Furthermore, various cathode catalyst systems have been developed with high-mass activities to decrease the amount of used platinum [31-35], yet few transferred these high mass activities into the expected high power output in a single-cell configuration [36,37]. The reason for this could be the very complex nature of the MEA and its operating conditions, for which it is difficult to identify all the crucial parameters in electrode composition that need to be optimized and to precisely control all parameters during operation. Namely, highly kinetic activities for oxygen reduction reactions (ORR), as measured in half-cell liquid electrolyte setups, often do not necessarily translate into high power outputs in the solid electrolyte MEAs. At the same time, one parameter that certainly has a high influence on power output is the finite diffusion of the reactant gases to the active sites. One means of influencing the mass transport of gases is by their ionomer content $[4,27,28]$. While enough ionomers need to be present to enable good proton conductivity, too much ionomer content inhibits mass transport by retaining larger amounts of product water and by forming thicker polymer films around the catalyst [4,27]. In the humidity range of 30 to $60 \%$ relative humidity (cathode), optimal ionomer content was determined to be between 25 and $40 \mathrm{wt} \%$ with an ionomer-to-carbon (I/C) ratio between 0.7 and $1[27,28]$. In addition, investigations in a very early stage of PEMFC technology showed that the porosity and thickness of the active layer and GDL play an important role in the diffusion processes [29]. More recent experimental studies performed by J. Lee et al. could find hard evidence for the nature of this effect [38]. Using synchrotron X-ray radiography, the liquid water content of two GDLs with identical material and of different thickness was determined. Using EIS, it was determined that the diffusion resistance was increased for the GDL, which was $80 \mu \mathrm{m}$ thicker. The presented EIS data also revealed an influence on the electrolyte resistance. Since the thicker GDL retained more liquid water, the membrane was better wetted and more conductive of protons. This led to an average decrease of the high-frequency resistance (electrolyte resistance) by $9 \times 10^{-3} \Omega \mathrm{cm}^{2}$ ( 10\% of the measured values).

Another, less-studied way to influence mass transport could be the thickness of the catalyst layer, as the mean diffusion length of the gases will be higher for thicker catalyst layers. The first signs of this effect were measured by N. Wagner et al. in their studies on electrode composition, however, the effect was not the focus of that particular study [7]. To study the gas-permeability properties of a catalyst layer it is important to know that the ink composition (I/C ratio, solid content), rheological properties and method of coating strongly influence the proton- and oxygen-transport properties of the resulting catalyst layer $[39,40]$. It is important to control these parameters during experiments concerned with studying the oxygen permeability of catalyst layers.

The influence of platinum distribution on the diffusion resistance was investigated by J. P. Owejan et al. and a small change in transport resistance was observed when varying 
the platinum's dispersion at low platinum loadings of $0.025 \mathrm{mg} \mathrm{Pt}_{\mathrm{Pt}} / \mathrm{cm}^{2}$ [30]. A model describing the impact of catalyst-layer geometry on water management was presented in the early 2000s and came to the conclusion that the porosity and thickness of the catalyst layer determine the water-content and wetting properties of the catalyst layer and membrane [41]. However, to the best knowledge of the authors, there is no thorough experimental study in the literature concerning the effect of the catalyst layer thickness on the transport of gases to the active sites and its effect on EIS signals.

The scope of this work is to present an equivalent circuit model, which includes both approaches presented by Wagner-Schulze and Pivac-Klotz [7,8,11,42] for complete simulation of the low frequency impedance spectrum. Experimental data obtained from in-house manufactured MEAs is presented and the combined model is applied for the optimization work of the catalyst-layer structure and the identification of crucial parameters influencing voltage loss during polarization.

\section{Experimental}

\subsection{Materials and Methods}

All materials used were standard components already well-studied in the literature, to exclude unknowns from material properties.

Two platinum-on-carbon analogues, HiSpec 3000 (nominally $20 \mathrm{wt} \%$ Pt on carbon) and HiSpec 4000 (nominally $40 \mathrm{wt} \% \mathrm{Pt}$ on carbon), were used as catalysts to fabricate catalyst layers. NS $5 \mathrm{Nafion}$-ionomer dispersion of $5 \mathrm{wt} \%$ in water/isopropanol was used and purchased from QuinTech (QuinTech e.K., Göppingen, Germany). The electrolyte for RDECV measurements consisted of Merck, Suprapur, $70 \%$, diluted by Milli-Q, $18.2 \mathrm{M} \Omega \mathrm{cm}$. $\mathrm{Ag} \mid \mathrm{AgCl}$ was used as a reference and a Pt wire as a counter electrode. The working electrode was a glassy carbon disc embedded in Teflon (Pine Instruments Company, Grove City, PA, USA) with a geometric surface area of $0.196 \mathrm{~cm}^{2}$. Polishing paste for the working electrode was $\mathrm{Al}_{2} \mathrm{O}_{3}$ paste with particle size $0.05 \mu \mathrm{m}$ purchased from Buehler (Buehler AG, Uzwil, Switzerland).

For MEA preparation, standard NM212 Nafion membranes with a thickness of $50 \mu \mathrm{m}$ were used to minimize hydrogen crossover effects during the experiments. Sigracet 39 BC carbon coated carbon paper was used as GDL.

An ExactaCoat OP3 Ultrasonic Spray Coater (Sono-Tek Corporation, Milton, NY, USA) with a $120 \mathrm{kHz}$ nozzle was used to prepare catalyst coated membranes with exact thickness control.

The cell hardware consisted of a $25 \mathrm{~cm}^{2}$ single cell (S++ simulation services, MurnauWestried, Germany), using a triple serpentine flow field on both sides. The integrated segmented plate allows the measurement of current and temperature distribution. Current and potential were controlled by a Zahner IM6ex potentiostat combined with a PP240 power-potentiostat for high current loads (Zahner-elektrik GmbH \& Co. KG, KronachGundelsdorf, Germany). For RDE-CV a CompactStat (Ivium Technologies B.V., Eindhoven, The Netherlands) potentiostat was used.

\subsection{MEA Preparation and Single Cell Assembly}

Electrocatalyst ink preparation-Two different catalyst inks were used for this study. One containing the HiSpec 3000 and the other containing the HiSpec 4000 catalyst. In both cases, the ionomer content within the ink was kept constant at $30 \mathrm{wt} \%$ of the dry electrocatalyst mass. This resulted in I/C ratios of 0.8 for HiSpec 4000 and 0.6 for HiSpec 3000. The mass concentration of electrocatalyst inks was $4 \mathrm{mg}_{\text {catalyst }}$ per $\mathrm{mL}$ of solvent. To obtain stable inks, ratio of 97:3 between 2-propanol and water (Milli-Q) was used.

Prior to the preparation of the catalyst-coated membranes (CCMs), all electrocatalyst inks were ultrasonicated for $45 \mathrm{~min}$ in an ice-cooled ultrasound bath.

Electrocatalyst loading determination and CCM preparation-For preparation of all the CCMs, an Ultrasonic Spray Coater (Sonotech ExactaCoat OP3) with a $120 \mathrm{kHz}$ nozzle was used. Three MEAs were prepared with varying cathode compositions. Two cathodes were 
prepared using the HiSpec 4000 catalyst with Pt-loadings of 0.125 and $0.250 \mathrm{mg}_{\mathrm{Pt}} \mathrm{cm}^{-2}$. One MEA was prepared with a cathode of HiSpec 3000 and $0.125 \mathrm{mg}_{\mathrm{Pt}} \mathrm{cm}^{-2}$. The Pt loading and the electrocatalyst were kept constant for the anode at $0.05 \mathrm{mg}_{\mathrm{Pt}} \mathrm{cm}^{-2}$ using the HiSpec 3000 catalyst. Prior to the preparation of the CCMs a gas diffusion layer (Sigracet $39 \mathrm{BC}$ ) was first coated to determine the number of necessary spraying cycles (weight per cycle) to reach the desired loading. For that, 60 layers of each catalyst ink were sprayed on the GDL. This experiment was performed three times to ensure repeatability. The mass change was noted and averaged to determine the weight of electrocatalyst per spraying cycle. For the preparation of the CCMs, the electrocatalyst inks were sprayed directly on the Nafion NM212 membrane, which was fixed on a heated, porous, PTFE substrate using vacuum suction. Care was taken to ensure that the surface temperature of the membrane fixed onto the substrate remained at $80 \pm 1^{\circ} \mathrm{C}$. After the spray process, the CCMs were left to dry on the substrate for fifteen minutes. The prepared MEAs are listed in Table 1.

Table 1. List of prepared membrane electrode assemblies (MEA). Catalyst-layer thickness was determined by cross sectional SEM imaging.

\begin{tabular}{|c|c|c|c|c|c|c|}
\hline Sample Name & $\begin{array}{c}\text { Anode } \\
\text { Loading } / \mathrm{mg} \mathrm{cm}^{-2}\end{array}$ & $\begin{array}{l}\text { Anode } \\
\text { Catalyst }\end{array}$ & $\begin{array}{c}\text { Cathode } \\
\text { Loading } / \mathrm{mg} \mathrm{cm}^{-2}\end{array}$ & Cathode Catalyst & $\begin{array}{l}\text { Cathode Ionomer } \\
\text { Content } / w t \%\end{array}$ & $\begin{array}{c}\text { Cathode Catalyst } \\
\text { Layer } \\
\text { Thickness/um }\end{array}$ \\
\hline MEA 40/0.125 & 0.05 & \multirow{3}{*}{ HiSpec 3000} & 0.125 & HiSpec 4000 & $30(\mathrm{I} / \mathrm{C}=0.8)$ & 4.4 \\
\hline MEA 40/0.250 & 0.05 & & 0.250 & HiSpec 4000 & $30(\mathrm{I} / \mathrm{C}=0.8)$ & 11.7 \\
\hline MEA 20/0.125 & 0.05 & & 0.125 & HiSpec 3000 & $30(\mathrm{I} / \mathrm{C}=0.6)$ & 11.7 \\
\hline
\end{tabular}

\subsection{Electrochemical Measurements (RDE-CV, In-Situ ECSA, Single Cell Polarization and EIS Measurements)}

$R D E-C V$ measurements were performed to determine the difference in activity and electrochemically active surface area (ECSA) between the two commercially available catalysts used in this study, supporting the determination of structural differences using STEM measurements. These were conducted in a two-compartment electrochemical cell in $0.1 \mathrm{M}$ $\mathrm{HClO}_{4}$ electrolyte with a conventional three-electrode system. The $\mathrm{Ag} \mid \mathrm{AgCl}$ reference was separated from both the working and counter electrode via a salt bridge to avoid $\mathrm{Cl}^{-}$ion contamination. Prior to each experiment, the two-compartment electrochemical cell was boiled in Milli-Q water for $1 \mathrm{~h}$, and the electrode was polished to a mirror finish with a polishing cloth and with $\mathrm{Al}_{2} \mathrm{O}_{3}$ paste. Then, $20 \mu \mathrm{L}$ of $1 \mathrm{mg} \mathrm{mL} \mathrm{m}^{-1}$ water-based well-dispersed electrocatalysts ink was pipetted on the glassy carbon electrode, completely covering it, and was dried under ambient conditions. Afterwards it was immersed in an Ar-saturated electrolyte under potential control at $0.05 \mathrm{~V}_{\mathrm{RHE}}$. Both electrocatalysts were electrochemically activated (EA) for 200 cycles between 0.05 and $1.2 \mathrm{~V}_{\text {RHE }}$ with a scan rate of $300 \mathrm{mV} \mathrm{s}^{-1}$ with $600 \mathrm{rpm}$ of rotation. After EA, the electrolyte was exchanged with a fresh one and the electrode was removed from external potential control (i.e., the conditions corresponded to the open circuit potential-OCP). ORR polarization curves were measured in an oxygen-saturated electrolyte with rotation at $1600 \mathrm{rpm}$ in the potential window $0.05-1.0 \mathrm{~V}_{\text {RHE }}$ with a scan rate of $20 \mathrm{mV} \mathrm{s}^{-1}$. For ECSA determination by CO-stripping, the electrolyte was purged with $\mathrm{CO}$ under potentiostatic mode $\left(0.05 \mathrm{~V}_{\mathrm{RHE}}\right)$ to ensure successful $\mathrm{CO}$ adsorption. Afterwards the electrolyte was saturated with Ar. CO electrooxidation was performed using the same potential window and scan rate as in ORR, but without rotation and in an argon-saturated electrolyte. After subtraction of background current due to capacitive currents, kinetic parameters were calculated at $0.9 \mathrm{~V}_{\mathrm{RHE}}$ by using the Koutecky-Levich equation [43]. The electrochemically active surface area (ECSA $\left.{ }_{C O}\right)$ was determined by integrating the charge in CO-stripping experiments, as described in reference [44]. 
Cell assembly, break-in and in-situ ECSA measurement-The finished CCMs were placed in between two gas-diffusion layers (Sigracet $39 \mathrm{BC}$ ) and fixed into a commercial $25 \mathrm{~cm}^{2}$ testing-cell ( $\mathrm{S}++$ Simulation Services) using a triple serpentine flow-field on a graphite bipolar plate on both sides. After gas-tightness check, the cells were fixed into a fully automated in-house testing station with humidity monitoring shortly before and after the cell inlets to ensure correct reactant gas humidification. The gas inlet temperature was controlled at $85^{\circ} \mathrm{C}$ and cell temperature was kept at $80^{\circ} \mathrm{C}$. Electrochemical measurements were recorded using an IM6ex modular electrochemical workstation coupled with a PP240 power-potentiostat (Zahner-elektrik GmbH \& Co., KG, Kronach-Gundelsdorf, GER). Cell break-in consisted of a potential ramp-up and ramp-down $\left(3.3 \mathrm{mV} \mathrm{s}^{-1}\right)$, from 0.4 to $0.6 \mathrm{~V}$, by holding the potential for thirty seconds at $0.5 \mathrm{~V}, 0.6 \mathrm{~V}$ and $0.7 \mathrm{~V}$ in between. The reactant gases supplied during break-in were $600 \mathrm{~mL} \mathrm{~min}^{-1}$ air $/ \mathrm{H}_{2}$, at atmospheric pressure and $100 \%$ RH. Afterwards, hydrogen crossover was tested to ensure membrane integrity was not affected by the coating process and cell assembly. The cells were supplied with $\mathrm{H}_{2} / \mathrm{N}_{2}$

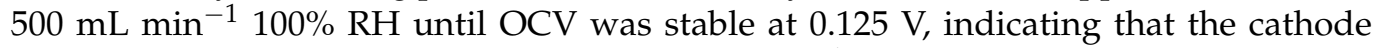
side was air-free. Then a linear sweep with $1 \mathrm{mV} \mathrm{s}^{-1}$ from OCV to $0.5 \mathrm{~V}$ was recorded. This was repeated for an excess pressure on the hydrogen side of 0 mbar, 50 mbar and 100 mbar. Membrane integrity was confirmed if the crossover current density did not exceed $15 \mathrm{~mA} \mathrm{~cm}^{-2}$ over the potential range of the sweep; it did not exceed $1 \mathrm{~mA} \mathrm{~cm}^{-2}$ for any MEA studied.

After the cross-over tests were successfully performed, the pressure difference between anode and cathode was reset to 0 mbar and the potential swept with $50 \mathrm{mV} \mathrm{s}^{-1}$ and between 70 and $600 \mathrm{mV}$ for three cycles to determine in-situ ECSA. The third cycle was used to calculate the ECSA from the HUPD—peak charge (determined via integration of the peak), using the specific platinum charge of $210 \mu \mathrm{C} \mathrm{cm}_{\mathrm{Pt}^{-}}{ }^{-2}$.

Single-cell polarization measurement was performed in the $25 \mathrm{~cm}^{2}$ cell using a triple serpentine flow field, initial gas conditioning was performed with gases bypassing the cell. Only when desired conditions were achieved were the gases supplied to the cell. All polarization curves were recorded with a reactant gas supply of $\mathrm{H}_{2}$ / air at $1.5 \mathrm{bar}(\mathrm{g})$, $60 \% \mathrm{RH}$ and $600 \mathrm{~mL} \mathrm{~min}^{-1}$ constant flow. This is equivalent to an air stoichiometry of 1.2 at the highest current density recorded $\left(1.2 \mathrm{~A} \mathrm{~cm}^{-2}\right)$, while over the whole polarization curve, the hydrogen stoichiometry was above 2.9. This way the influence of the anode's limitations can be neglected. All polarization points were recorded in galvanostatic mode, over a period of $5 \mathrm{~min}$, in steady state operation.

Electrochemical Impedance Spectra (EIS)_Operating points were held for at least five minutes before recording, to achieve steady-state conditions. The impedance was recorded between $50 \mathrm{kHz}$ and $0.1 \mathrm{~Hz}$ with an amplitude of $8 \%$ of the operating point. The operating conditions were kept exactly the same as for polarization recording. Simulation and fitting of the impedance spectra were performed with the software ZView ${ }^{\circledR}$ (Scribner Associates Inc., Sounthern Pines, NC, USA).

\subsection{Structural Analysis of the Catalyst Powders and MEA Cross Sections}

Structural TEM analysis of the two catalyst powders was carried out in a probe Cscorrected scanning transmission electron microscope Jeol ARM 200 CF equipped with a SDD Jeol Centuria Energy-dispersive X-ray (EDX) spectrometer. The operational voltage was set to $80 \mathrm{kV}$. High-angle annular dark field (HAADF) images were taken with at 68 and $180 \mathrm{mrad}$ for the inner and outer semiangles. The convergence angle was set to $25 \mathrm{mrad}$.

SEM analysis of the MEA cross sections was carried out in a field emission scanning electron microscope Zeiss Ultra+ equipped with an SDD X-MAX 50 Energy-dispersive X-ray (EDX) spectrometer. Cross-sectional images were taken at $1 \mathrm{kV}(50 \mathrm{pA})$ with standard secondary electron (SE) detector. Phase-contrast images were acquired with an Energy Selective Backscattered detector (EsB) at $1 \mathrm{kV}(50 \mathrm{pA})$ and the energy-filtering grid was set to $400 \mathrm{~V}$. EDX analysis was acquired at $7 \mathrm{kV}$ with a probe current set to $200 \mathrm{pA}$. Prior 
to the SEM analysis, cryo-cut samples were mechanically prepared by razor blade while submerged in liquid nitrogen.

The powder X-ray diffraction (XRD) measurements of the benchmark catalysts were carried out on a PANalytical $X^{\prime}$ Pert PRO MPD diffractometer with $\mathrm{Cu} \mathrm{K} \alpha 1$ radiation $(\lambda=1.5406 \AA)$ in the $2 \theta$ range from $10^{\circ}$ to $60^{\circ}$ with a 0.034 o step per $100 \mathrm{~s}$, using a fully opened $X^{\prime}$ Celerator detector. Samples were prepared on a zero-background Si holder.

\subsection{Simulation}

For the construction of our new equivalent circuit model, the base models from literature were integrated and extended in order to ensure the correct simulation of the low frequency range of EIS. In addition, it is important to estimate the correct order of magnitude of the starting values in order to find meaningful parameter values to the measured data. Otherwise, the fitting algorithm could be trapped in a local minimum and could find a solution with physically impossible values.

Therefore, a first visual inspection of our impedance spectra was performed to get first estimates of the parameters and the underlying processes. With these estimates, the values of the equivalent circuit model from Wagner, Schulze et al. (see Figure 1a) were evaluated in a second step.

This equivalent-circuit model, called Model 1 hereafter, consists of a resistance $R_{\text {mem }}$ illustrating the membrane resistance. Then three R-CPE elements are in series with $R_{\text {mem }}$. The first two R-CPE elements $\left(R_{c t, a}-C P E_{a}, R_{c t, c}-C P E_{c}\right)$ represent the charge transfer at the anode and cathode side, respectively, and the electrochemical double layer capacitance between the respective electrodes and electrolyte.

The third $\mathrm{R}_{\mathrm{mt}}-\mathrm{CPE}_{\mathrm{mt}}$ element stands for the finite diffusion of the oxygen through the gas diffusion layer and catalyst layer to the active sites and can be associated with the NFLI-loop in the impedance spectra [7-11]. The starting point of our proposed extended equivalent circuit model, called Model 2 hereafter, is the equivalent circuit model illustrated in Figure $1 b$. In this model, the membrane resistance $R_{\text {mem }}$ is again in series with the $\mathrm{R}_{\mathrm{ct}, \mathrm{a}}-\mathrm{CPE} \mathrm{E}_{\mathrm{a}}$ element and in series with a Randles circuit, that describes the charge transfer and the electrochemical double layer capacitance at the cathode side $\left(R_{c t, c}, C P E_{c}\right)$ and the diffusion of oxygen to the active sites $\left(Z_{W}\right)$.

In a next step, the finite length Warburg impedance is substituted by an $R_{m t}-C P E_{m t}$ element (see Figure 1c). This simplification is justified because the finite length Warburg element can be also represented as a finite series connection of R-CPE elements, which can be combined to one R-CPE element [45-49]. Until now, the semicircles for the charge transfer at both electrodes as well as the NFLI-loop can be evaluated, but the PFLI-loop is neglected. Therefore, to conclude Model 2, the equivalent circuit model of D. Klotz is incorporated into the model by placing an $\mathrm{R}_{\text {intermediate }}-\mathrm{CPE}_{\text {intermediate }}$ element in series with $R_{c t, c}$ and the $R_{m t}-C P E_{m t}$ element (see Figure $1 d$ ). The values of $R_{\text {intermediate }}$ and $Q$ in the $\mathrm{CPE}$ intermediate are negative.

As all impedance spectra are recorded in the linear region of polarization curve, an estimate for $R_{\text {intermediate }}$ can be found by subtracting the low frequency intercept of the real axis from the slope of the polarization curve at the respective operating point. In all cases the resistance estimate was approximately $-7 \mathrm{~m} \Omega$. Value estimates for the negative $Q$ value of the CPE were obtained from the time constant at which the maximum of the PLFI-loop was identified in the spectrum. 
a)

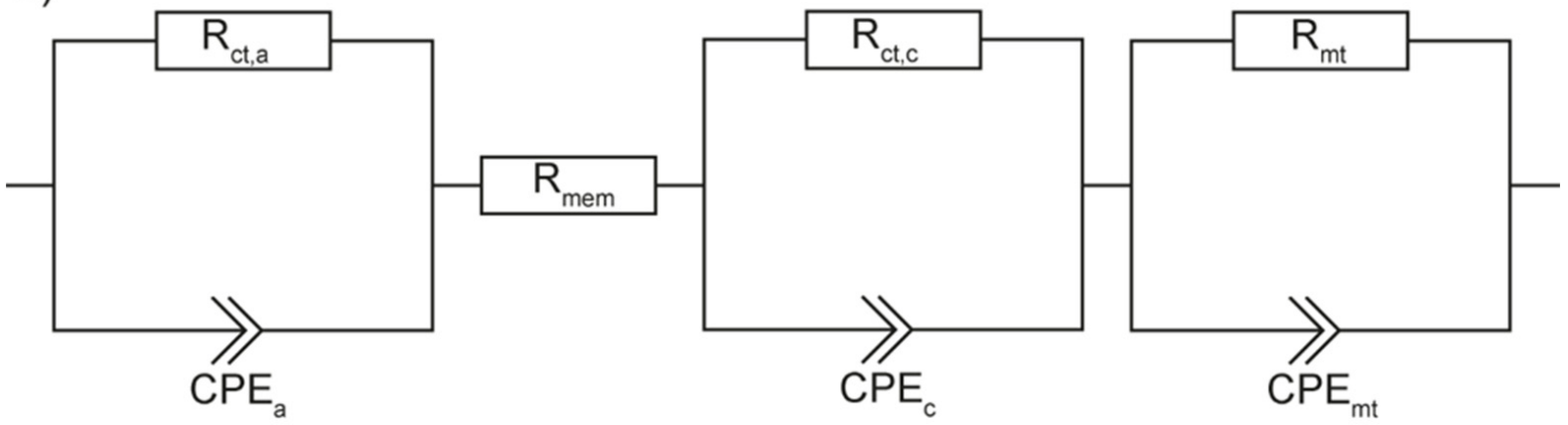

b) $R_{c, a}$

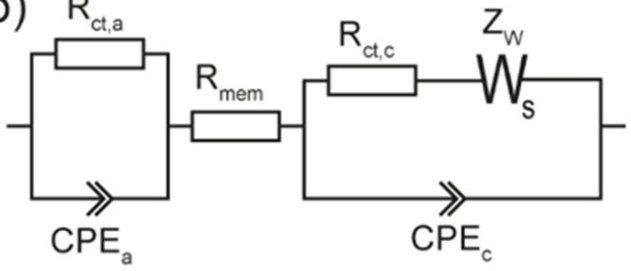

C) $R_{c t a}$

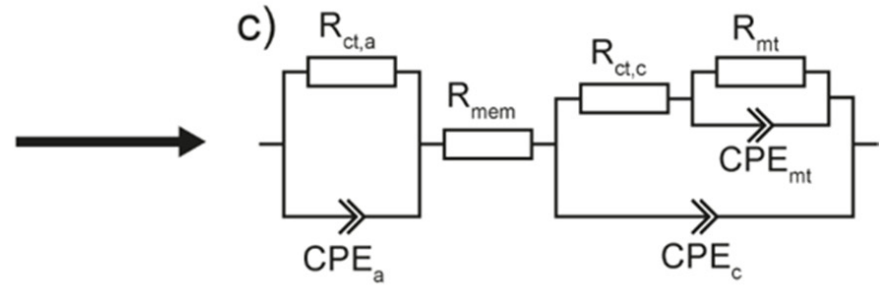

d)

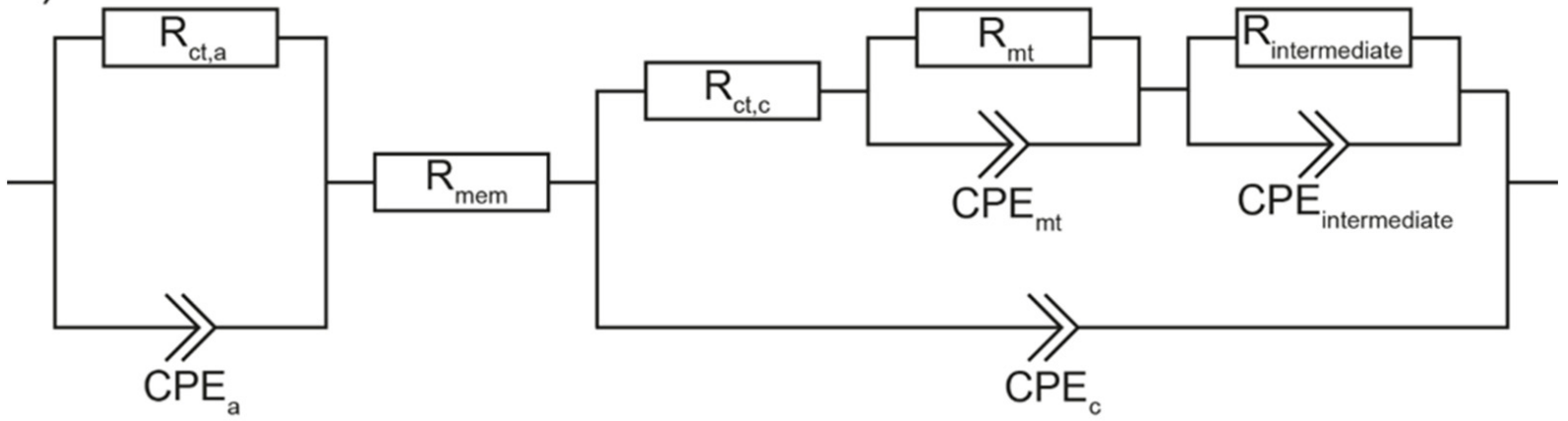

Figure 1. Summary of the equivalent circuit models used in the literature: (a) equivalent circuit proposed by Wagner, Schulze at al. (Model 1); (b) equivalent circuit using a R-CPE element for the charge transfer at anode side and a Randles circuit for the charge transfer at the cathode and the diffusion of oxygen $\left(Z_{W}\right)$; (c) equivalent circuit to that in Figure $1 b$ in which the finite Warburg element has been changed to a R-CPE element; (d) our proposed model (Model 2).

To consider the inductivity of the measuring cables both models, Model 1 and Model 2 , have an inductance in series to $R_{\text {mem }}$.

To check for physical correctness, the following criteria were used:

- The characteristic frequency of each RC-element should be in the correct order of magnitude: 1.1-1.4 Hz for $R_{m t}, 50-200 \mathrm{~Hz}$ for $R_{c t, c}$ and $600-3000 \mathrm{~Hz}$ for $R_{c t, a}$.

- The sum of all positive resistances should be equal to the low-frequency intercept in the corresponding EIS spectrum.

- $\quad$ For the CPE, values of $\mathrm{P}$ should be $0<p \leq 1$.

- Kramers-Kronig (K-K) and ZHIT analysis was performed on the measured impedance data. For more detailed information, see supporting information.

To check for numerical correctness, the following criteria were used:

- $\quad$ The sum of squares should be below 0.1 .

- The element error of fit must be $<10 \%$ for each parameter. This means that the goodness of fit starts to change significantly when the value changes by $10 \%$.

- $\quad$ The relative residuals between simulated and measured data were calculated. For more detailed information, see supporting information. 


\section{Results and Discussion}

Cross sectional SEM results in Figure 2 and the summary in Table 2 show that the catalyst layer thickness is increased either by keeping the catalyst loading constant and decreasing the ratio of platinum in the catalyst, or by increasing the loading. While a catalyst layer using HiSpec 4000 with $40 \mathrm{wt} \% \mathrm{Pt}$ on carbon and $0.125 \mathrm{mg}_{\mathrm{Pt}} \mathrm{cm}^{-2}$ resulted in an average thickness of $4.4 \mu \mathrm{m}$, the thickness increased by the factor 2.7 when the catalyst was changed to HiSpec 3000 with $20 \mathrm{wt} \%$ Pt on carbon. On the other hand, when the loading was reduced by a factor of 2.5 with the same ink-composition, the thickness decreased by a factor of 2.7 .

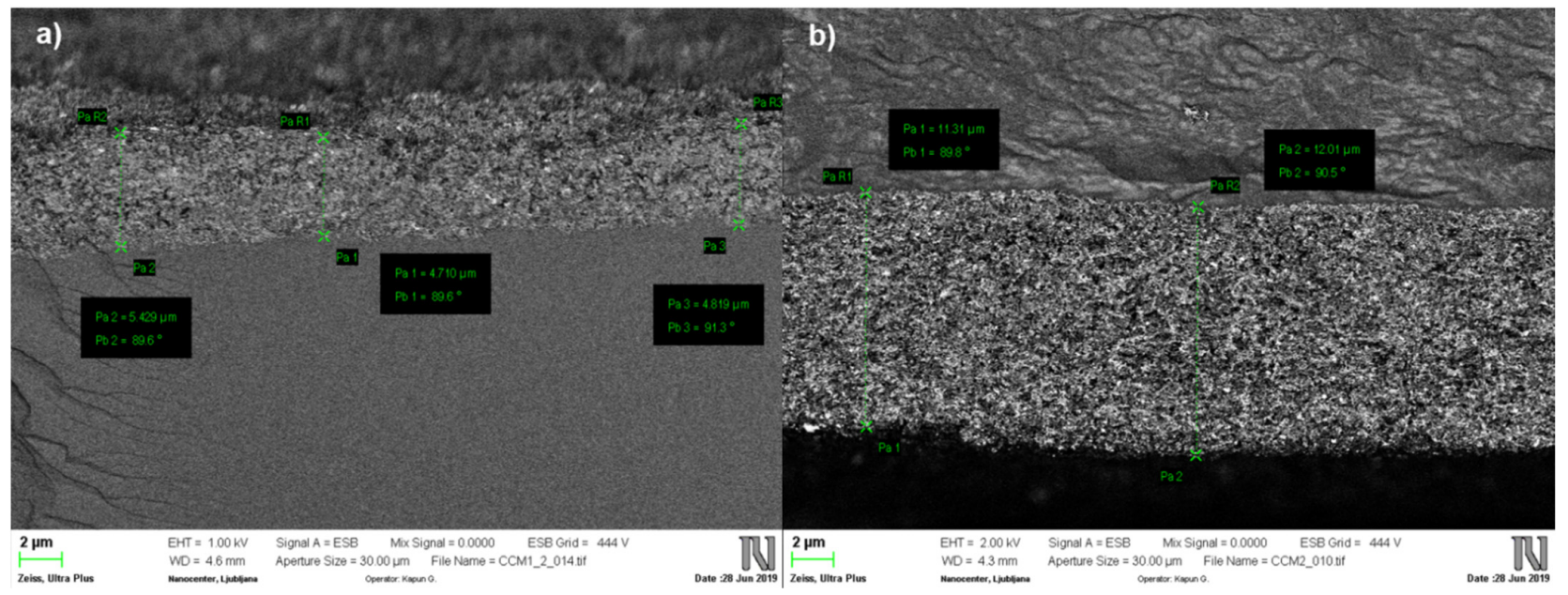

Figure 2. Cross sectional SEM of prepared catalyst layers used for layer-thickness determination of: (a) MEA 40/0.125, (b) MEA 20/0.125.

Table 2 shows that acceptably high precision and repeatability was achieved with the coating process. The error in between different spraying processes was determined to be $7.0-8.0 \%$, confirming good repeatability. The good uniformity of the sprayed material is indicated by the low random deviation of the thickness at different locations of the same sample (2.2-5.7\%).

STEM and XRD analysis of the catalyst powders, reported in Figure 3, showed that lower platinum content led to a finer distribution of the platinum and therefore smaller particle sizes. On average, the platinum particles are smaller on HiSpec 3000 with $20 \mathrm{wt} \%$ of platinum on carbon then on HiSpec 4000 with $40 \mathrm{wt} \%$ of platinum on carbon.

Table 2. Thickness and mass change of catalyst layers (anode and cathode) calculated from cross-sectional SEM images of MEA 40/0.125, MEA 20/0.125 and three purposefully prepared anodes, using the same composition as the HiSpec 3000 cathode, with $0.05 \mathrm{mg}_{\mathrm{Pt}} \mathrm{cm}^{-2}$ loading. The mass-change experiment was repeated three times for each catalyst.

\begin{tabular}{|c|c|c|c|c|c|}
\hline $\begin{array}{l}\text { Catalyst Layer } \\
\text { (CL) }\end{array}$ & $\begin{array}{c}\text { Average Thickness of } \\
\text { SEM Cross Section } \\
{[\mu \mathrm{m}]}\end{array}$ & $\begin{array}{c}\text { Error of } \\
\text { Measurement at Six } \\
\text { Different Locations } \\
\text { in One CL } \\
{[\%]}\end{array}$ & $\begin{array}{c}\text { Error over Three } \\
\text { Separately Prepared CL } \\
{[\%]}\end{array}$ & $\begin{array}{c}\text { Mass Difference after } \\
60 \text { Deposited Layers } \\
{[\mathrm{mg}]}\end{array}$ & $\begin{array}{c}\text { \% Error in Mass } \\
\text { Difference }\end{array}$ \\
\hline $\begin{array}{l}\text { Cathode: } \\
\text { HiSpec } 4000\end{array}$ & $4.4 \pm 0.3$ & 5.7 & & $5.8 \pm 0.4$ & 7.0 \\
\hline $\begin{array}{l}\text { Cathode: } \\
\text { HiSpec } 3000\end{array}$ & $11.7 \pm 0.3$ & 2.2 & & $5.4 \pm 0.4$ & 8.0 \\
\hline $\begin{array}{c}\text { Anodes: } \\
\text { HiSpec } 3000\end{array}$ & $4.4 \pm 0.3$ & 5.7 & 6.9 & $5.4 \pm 0.4$ & 8.0 \\
\hline
\end{tabular}



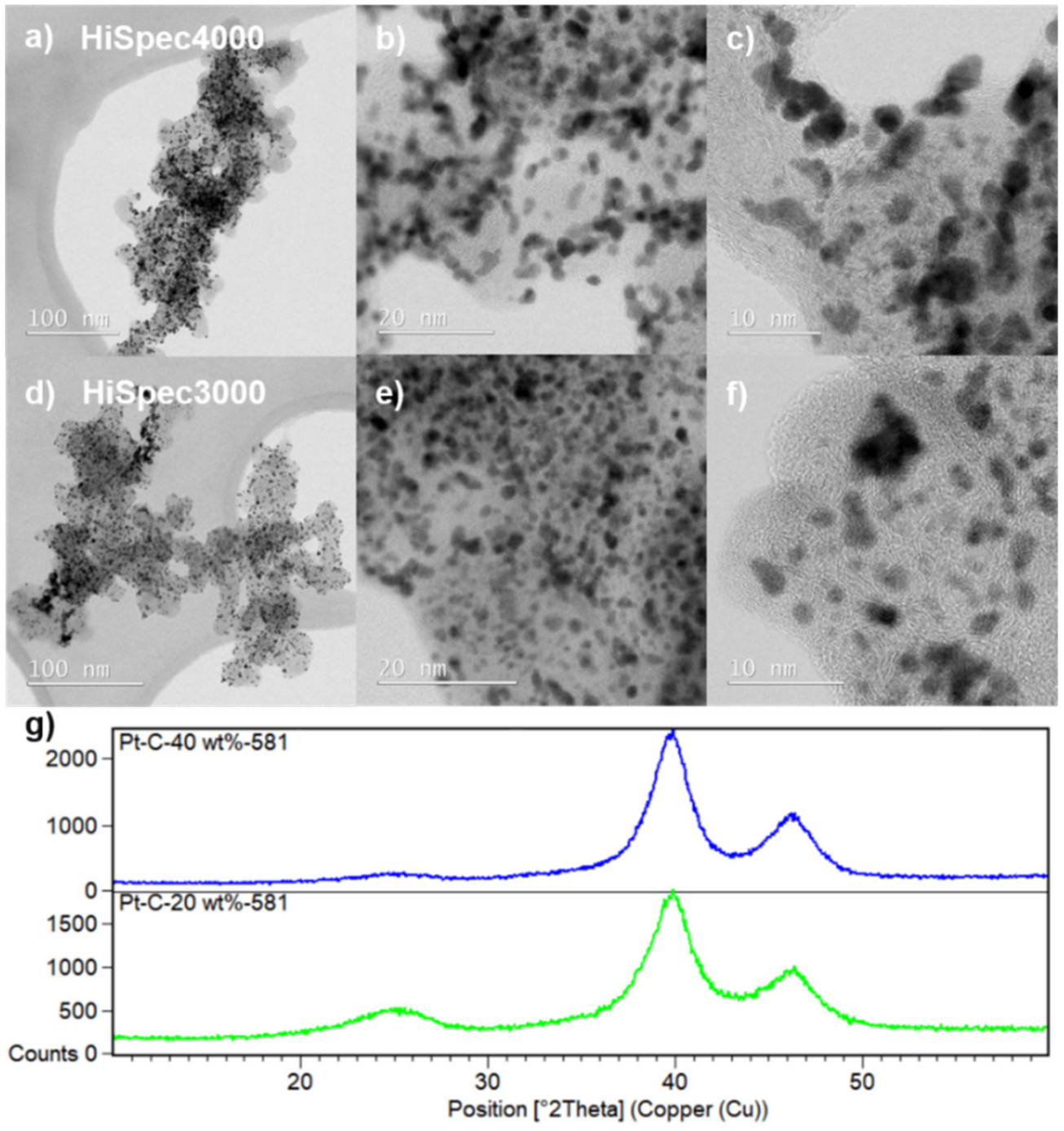

Figure 3. STEM BF images of Pt/C (a-c) HiSpec 3000 and (d-f) HiSpec 4000 at different magnifications and powder XRD spectra of the two catalysts (g). Samples were observed in unprocessed powder form.

The XRD spectra show that platinum crystallite size is increasing in the following order: Hi-spec 3000 < Hi-spec 4000. According to the conclusions made by J. P. Owejan et al. [30] this should lead to slightly increased diffusion resistance at the same catalyst layer thickness for the MEA using HiSpec 4000. Additional factors influencing oxygen and proton transport in the catalyst layer are the I/C ratio and rheological properties of the ink used for the coating process $[39,40]$. Since the I/C ratio is slightly lower in the HiSpec 3000 catalyst layers, the porosity and ionomer distribution will inherently be different then in HiSpec 4000 catalyst layers. In summary, the resistance stemming from oxygen transport increases with decreasing platinum surface area under constant platinum loading and with the same ink composition of the coating process.

Results of RDE-CV analysis can be seen in Figure 4. The values for mass activity, surface activity and ECSA are found in Table 3. These show very well that the catalysts have very similar specific (surface) activities, indicating that the particles have very similar crystal lattice structures at the surface. However, the much larger ECSA of HiSpec 3000, results in an almost doubled mass activity. This is the effect of the finer distribution of $\mathrm{Pt}$ on the carbon surface, leading to smaller particles. 
Table 3. Results of RDE-CV and in-situ CV analysis of the used catalyst powders.

\begin{tabular}{|c|c|c|c|c|c|c|c|c|}
\hline Sample & $\begin{array}{l}\mathrm{m}_{\mathrm{e}-\mathrm{cat}} \\
{[\mu \mathrm{g}]}\end{array}$ & $\begin{array}{c}\mathrm{Pt} \\
{[w \mathrm{t} \%]}\end{array}$ & $\begin{array}{c}\text { CO-Area } \\
{\left[\mathrm{cm}^{2}\right]}\end{array}$ & $\begin{array}{c}\mathrm{ECSA}_{\mathrm{CO}} \\
{\left[\mathrm{m}^{2} \mathbf{g}^{-1} \mathrm{Pt}\right]}\end{array}$ & $\begin{array}{c}\text { SA @ } 0.9 \mathrm{~V}_{\mathrm{RHE}} \\
{\left[\mathrm{mA} \mathrm{cm} \mathrm{cm}^{-2} \mathrm{Pt}\right]}\end{array}$ & $\begin{array}{c}\mathrm{MA} @ 0.9 \mathrm{~V}_{\mathrm{RHE}} \\
{\left[\mathrm{A} \mathrm{mg}^{-1} \mathrm{Pt}_{\mathrm{Pt}}\right]}\end{array}$ & $\begin{array}{c}\text { SA @ } 0.95 \mathrm{~V}_{\mathrm{RHE}} \\
{\left[\mathrm{mA} \mathrm{cm} \mathrm{cm}^{-2} \mathrm{Pt}\right]}\end{array}$ & $\begin{array}{c}\mathrm{MA} @ 0.95 \mathrm{~V}_{\mathrm{RHE}} \\
{\left[\mathrm{A} \mathrm{mg}^{-1} \mathrm{Pt}\right]}\end{array}$ \\
\hline $\begin{array}{c}\mathrm{Pt} / \mathrm{C} \\
\text { HiSpec } 3000\end{array}$ & 20 & 20 & 3.49 & 87.29 & 0.58 & 0.50 & 0.10 & 0.09 \\
\hline $\begin{array}{c}\mathrm{Pt} / \mathrm{C} \\
\text { HiSpec } 4000\end{array}$ & 20 & 40 & 4.28 & 53.47 & 0.64 & 0.34 & 0.11 & 0.06 \\
\hline
\end{tabular}

The results of the in-situ ECSA measurements are seen in Figure 5b. Evaluation showed that in-situ ECSA values are very similar for the cathodes of MEA 40/125 and MEA 40/250 as they were prepared using the same ink-composition. The value calculated from the HUPD peak integral was $43 \mathrm{~m}^{2} \mathrm{~g}^{-1}$ for MEA 20/0.125, while it amounted to 33 and $35 \mathrm{~m}^{2} \mathrm{~g}^{-1}$ for MEA 40/0.250 and MEA 40/0.125, respectively. The last two were prepared using the same ink, while the first one had a slightly lower I/C ratio (0.6 vs. 0.8$)$ and HiSpec 3000 as a catalyst. This is consistent with the results of ex-situ ECSA-HiSpec 3000 had a much higher ECSA then HiSpec 4000. There seems to be a difference between the in-situ and ex-situ values. While ex-situ ECSA was generally higher and increased by a factor of 1.6 (comparing HiSpec 4000 vs. HiSpec 3000), in situ the factor was 1.3. This is attributed to the difference in I/C-ratio between the HiSpec 3000 and HiSpec 4000 catalyst layers and the general difference in the measurement setups (different electrolyte and atmosphere). Nevertheless, the trend is very similar.
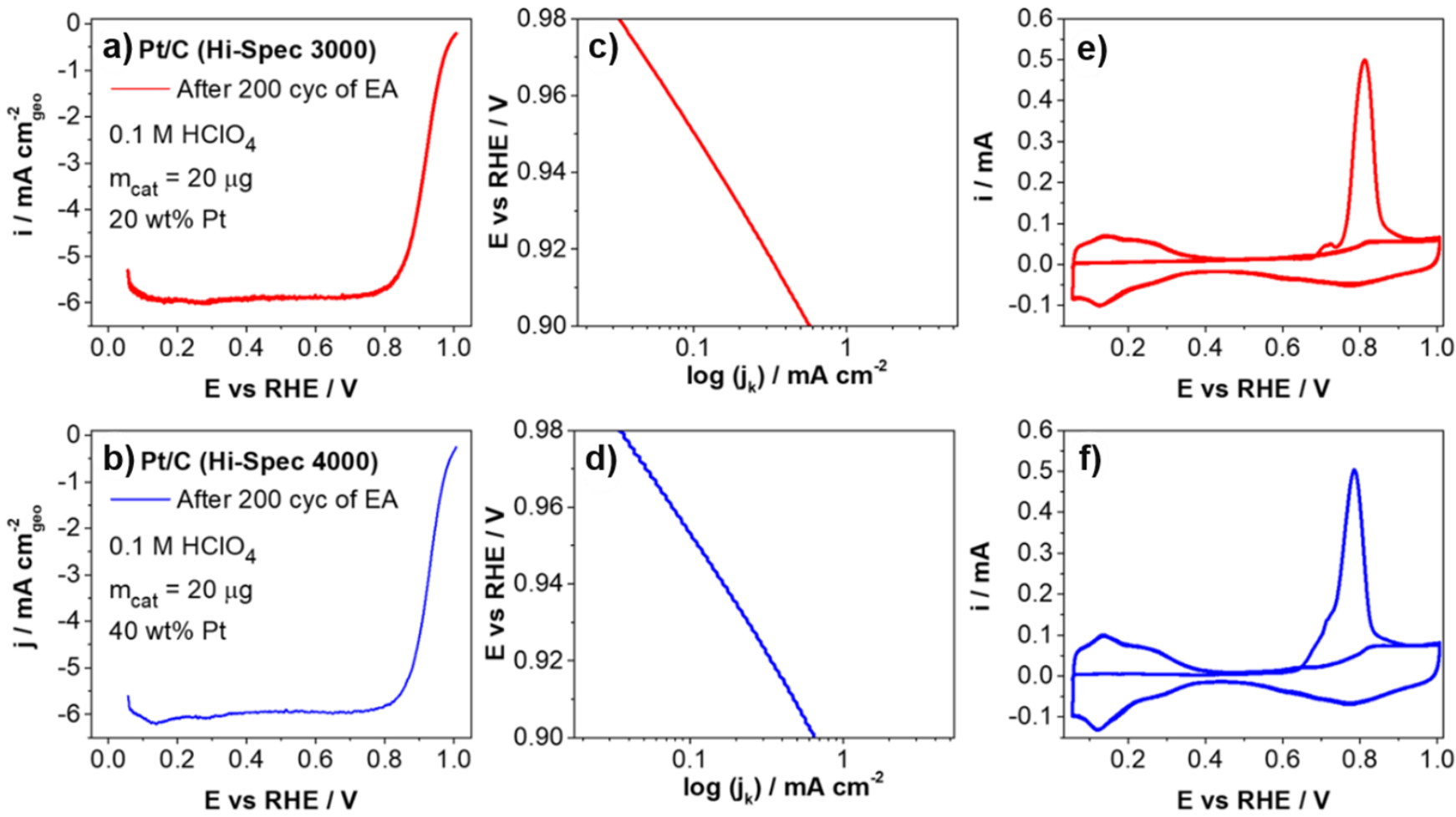

Figure 4. Comparison of activities and ECSAs of HiSpec 3000 and HiSpec 4000, determined on RDE-CV. (a,b) Oxygenreduction reaction CV at $1600 \mathrm{rpm}$ for HiSpec 3000 and 4000, (c,d) Tafel plots for HiSpec 3000 and 4000 and (e,f) CO electro oxidation CV for HiSpec3000 and 4000. 

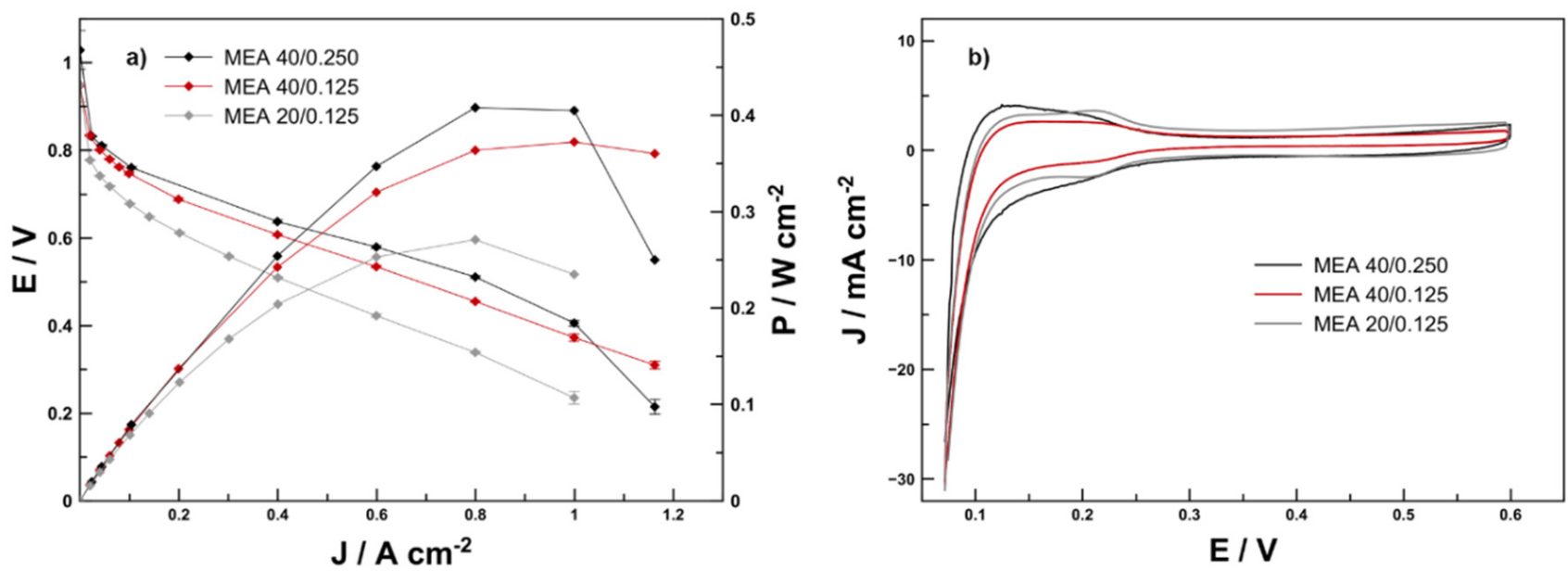

Figure 5. Polarization curves recorded using H2/SA $600 \mathrm{~mL} \mathrm{~min}^{-1}$ fixed flow at $60 \% \mathrm{RH}$ and $1.5 \mathrm{bar}(\mathrm{g})$ (a) and in-situ ECSA measurement recorded using $\mathrm{H}_{2} / \mathrm{N}_{2}$ at $100 \% \mathrm{RH}$ and atmospheric pressure (b) of the investigated MEAs. Error bars in polarization data represent the deviation of cell potential signals over the recording period.

The polarization curves of the three membrane electrode assemblies are compared in Figure 5a. As expected, MEA 40/0.250 showed the highest performance with peak power density of $404 \mathrm{~mW} \mathrm{~cm}^{-2}$.

In contrast MEA 40/0.125 showed a performance of $390 \mathrm{~mW} \mathrm{~cm}^{-2}$ and MEA 20/0.125

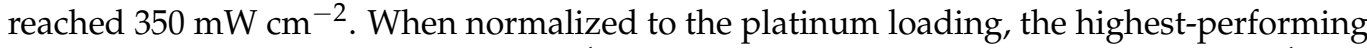
was MEA 40/0.125 with $2.3 \mathrm{~kW} \mathrm{gPt}^{-1}$ followed by MEA 20/0.125 with $2 \mathrm{~kW} \mathrm{gPt}^{-1}$ and MEA 40/0.250 with $1.4 \mathrm{~kW} \mathrm{~g}_{\mathrm{Pt}}{ }^{-1}$. Large deviation from linear behaviour is recognisable for MEA 40/0.250 and MEA 20/0.125 starting at $0.8 \mathrm{~A} \mathrm{~cm}^{-2}$. Contrary to this, MEA 40/0.125 shows only a small deviation from linear behaviour starting at $0.8 \mathrm{~A} \mathrm{~cm}^{-2}$. This is a sign for the influence of catalyst layer thickness: the two MEAs with a 11.7- $\mu \mathrm{m}$ thick catalyst layer seemed to be affected, to a greater degree, by diffusion limitation than the MEA 40/0.125 with a 4.4- $\mu \mathrm{m}$ thick catalyst layer. This is even more visible from the steeper drop in power density after the maximum power point is reached.

The EIS measurements were performed to determine the voltage loss contributions and confirm the presented equivalent circuit model. The model by N. Wagner (Model 1) and our extended model (Model 2) were used to simulate the curves. An exemplary simulation result, from each model, can be seen in Figure 6. The deviation between simulated and measured data is represented by the sum of squares and the relative residuals. In the case of Model 2, a low sum of squares of 0.07-0.02 at every operating point and with every MEA dataset was found.

Using Model 1, low values around 0.02-0.04 were only obtained when simulating in the negative impedance plane for low frequency, without consideration of data in the positive impedance plane. This can be seen as the inability of Model 1 to simulate a signal as soon as the imaginary impedance becomes positive again in the low-frequency region. This limitation is also clearly shown in Figure 6, as the simulation curve of Model 1 simply stops at the $x$-axis crossing and points that should appear in the positive impedance plane are simply shifted into the negative plain. This leads to high deviations from the dataset with a sum of squares between 0.1-0.3. Relative residuals between model and experimental data further show the high inaccuracy of Model 1.

Our extended Model 2 was able to correctly simulate the completely measured frequency range, including the PLFI signals with sum of squares of $0.02-0.05$, indicating the lower deviations of simulation and experimental data. Relative residuals between model and experimental data are very low and reach maximum values of $1 \%$ for all measured impedance spectra. For these reasons, the data calculated from Model 2 is much more trustworthy than data calculated by Model 1 . 

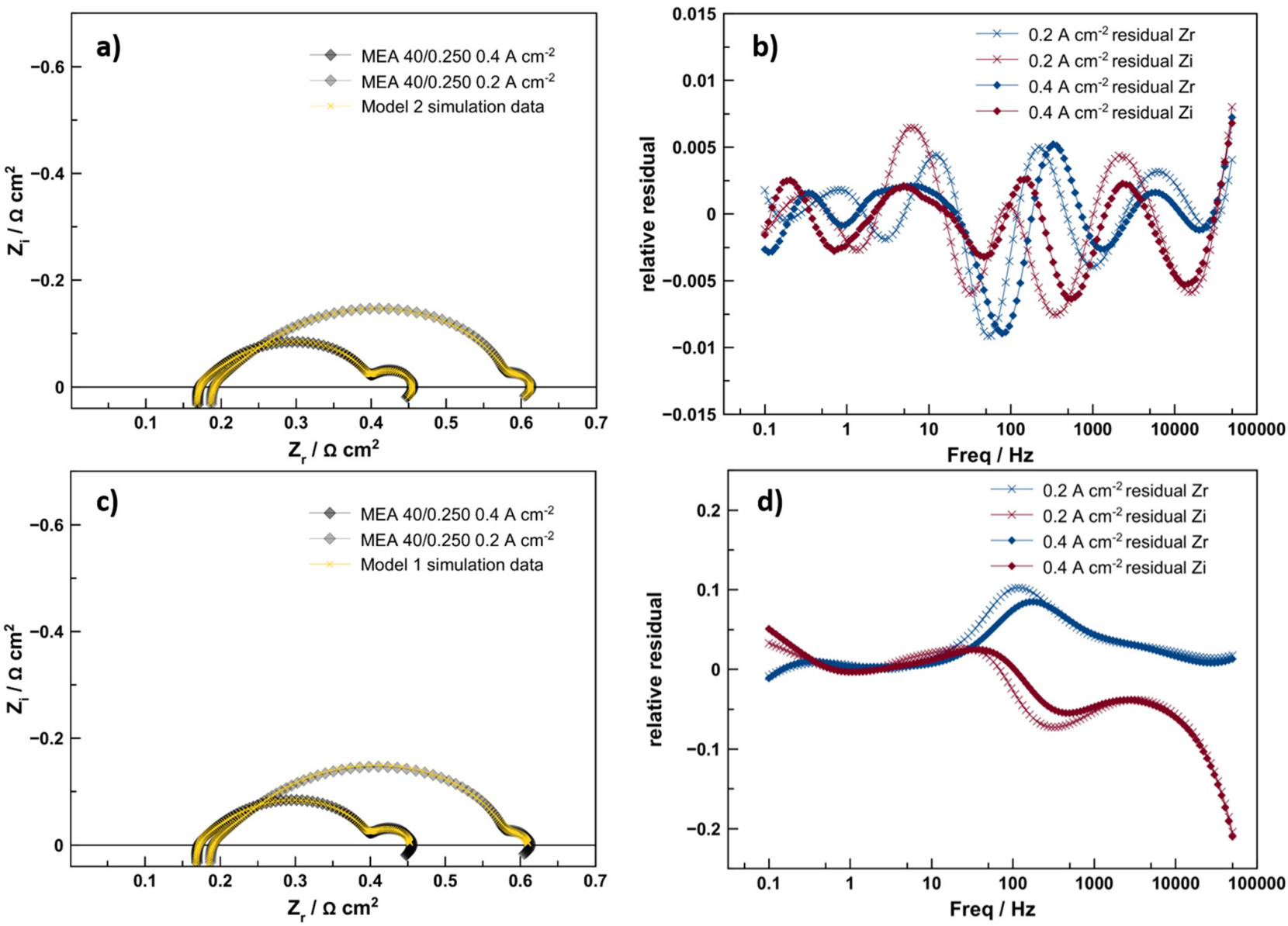

Figure 6. Selected experimental and simulated curves including residuals at 0.2, 0.4 of Model 2 (a,b) and Model 1 (c,d). The residuals show that Model 1 is not suited for simulating low-frequency signals, while Model 2 can simulate signals over the entire measured frequency spectrum. The complete set of experimental EIS-data and numerical residual analysis can be found in the supporting information (Figures S1-S5 in the Supplementary Materials).

The characteristic frequencies for the anode charge transfer elements obtained were in the region of 3000-600 Hz, while the cathode charge transfer elements resulted in characteristic frequencies of 400-60 Hz. Both models resulted in very similar characteristic frequencies for the equivalent circuit elements. Diffusion-related resistance elements resulted in much lower characteristic frequencies of $1-1.2 \mathrm{~Hz}$ and the corresponding semicircles are also well visible at the same frequency in the EIS data. These characteristic frequencies correspond to visible semicircle maxima in the measured impedance spectra.

The trend of the cathode charge transfer resistance, $R_{\mathrm{ct}, \mathrm{c}}$, in Figure 7 , is very similar if the results of Models 1 and 2 are compared and no significant change can be observed. A decrease of charge transfer resistance and an approximation to a final value is indicative of the kinetic nature of this resistance contribution. Overall, MEA 40/0.125 showed the highest $R_{c t, c}$, while MEA 20/0.125 and MEA 40/0.250 showed similarly lower values. This is consistent with the activity trend determined on the RDE (Figure 4). HiSpec 3000 was determined to be 1.5 times more active (mass activity) than HiSpec 4000 and MEA $40 / 0.250$ which contained $0.250 \mathrm{mg}_{\mathrm{Pt}} \mathrm{cm}^{-2}$ in the cathode, while MEA20/0.125 contained only $0.125 \mathrm{mg}_{\mathrm{Pt}} \mathrm{cm}^{-2}$ in the cathode.

The high-frequency resistance of the MEAs, which is the sum of the current collector's and electrolyte resistance, is strongly influenced by the catalyst-layer's thickness. MEA 40/0.125, with the thinnest catalyst layer, has the highest electrolyte resistance: the electrolyte resistance determined with Model 2 from the measured data is, on average, $9 \%$ lower for MEA 40/0.250 and 17\% lower for MEA 20/0.125 than the average electrolyte 
resistance of MEA 40/0.125. This is consistent with data and models presented by other researchers that show a clear impact of the thickness and porosity of the catalyst layer and the GDL on the water content in the electrodes and membrane $[38,41]$.
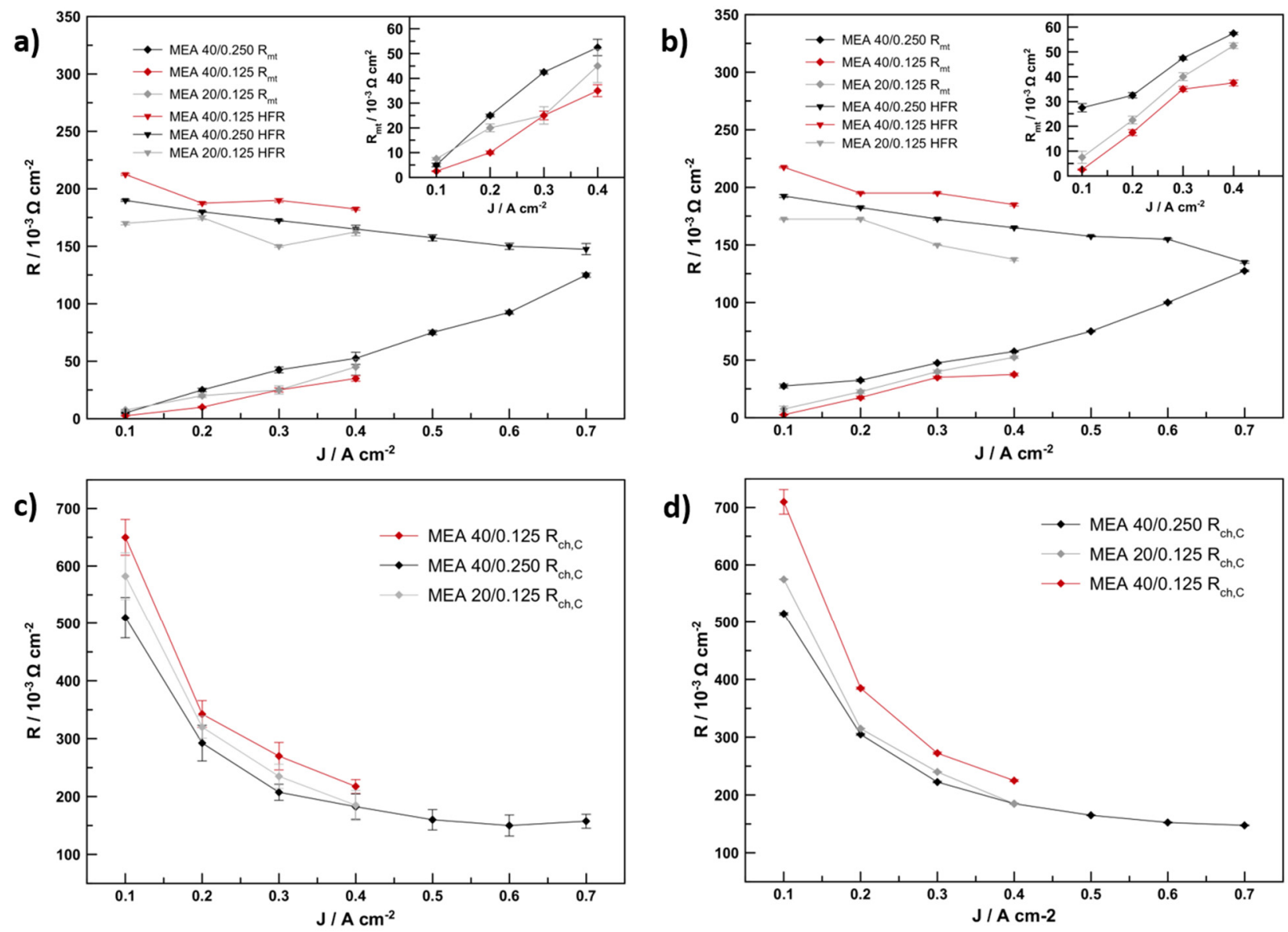

Figure 7. Trend of diffusion resistance $R_{m t}$ and cathode charge transfer resistance $R_{c t, c}$ with increasing catalyst layer thickness and current density obtained with $(\mathbf{a}, \mathbf{c})$ Model 1 and $(\mathbf{b}, \mathbf{d})$ Model 2. High-frequency resistance of all MEAs is shown for relation. Error bars represent the values at which the deviation of the model from the measured data starts to increase by more than $1 \%$ of the value.

The element errors for the diffusion related circuit elements were slightly higher for Model 1 at current densities between 0.3 and $0.7 \mathrm{~A} \mathrm{~cm}^{-2}$ than the errors calculated in Model 2. While Model 2 produced errors of 1.5 to $4 \%$, Model 1 produced errors of $6-10 \%$. Both models produced high errors of $>10 \%$ at $0.1 \mathrm{~A} \mathrm{~cm}^{-2}$, indicating their limits for the determination of diffusion resistance $\left(\mathrm{R}_{\mathrm{mt}}\right)$. This can be seen in Figure $7 \mathrm{a}, \mathrm{b}$ where the modelled diffusion resistance is plotted against the current density with the corresponding errors of fit shown as error bars. The trend described by both resistances confirms that a significant increase in diffusion resistance is the result of doubling catalyst layer thickness from 4.4 to $11.7 \mu \mathrm{m}$. EIS of MEA 40/0.125 (4.4 $\mu \mathrm{m}$ cathode catalyst layer) consistently resulted in lower $R_{\mathrm{mt}}$ values in the measured range then MEA 20/0.125 and MEA 40/0.250 (both $\sim 12 \mu \mathrm{m}$ cathode AL). In average $\mathrm{R}_{\mathrm{mt}}$ was $264 \%$ higher for MEA $40 / 0.250$ and $67 \%$ higher for MEA 20/0.125 than $R_{m t}$ determined for MEA 40/0.125. The difference in these numbers can be explained by the different current trend in $\mathrm{R}_{\mathrm{mt}}$ of MEA 20/0.125, which is in between that of MEA 40/0.250 and MEA 40/0.125 when considering Model 2. This could be either an effect of the slightly better platinum particle distribution and surface of the HiSpec 3000 catalyst (Figure 3), or the lower I/C ratio (0.6 vs. 0.8). Most probably, the sum of both effects was measured [30,39,40]. A mechanistic explanation for this increase in $\mathrm{R}_{\mathrm{mt}}$ can be found in the previously presented modelling and experimental studies. With 
similar electrode composition, the water content of the catalyst layer, membrane and GDL was found to be influenced by their thicknesses and porosities [38,41], with thicker layers retaining higher volumes of product water. These higher volumes of liquid water in the catalyst layer present a diffusion barrier that blocks the movement of the reactant gases to the active sites. While this effect was studied for the GDL in an experimental study by J. Lee et al. [38], it has only been theoretically discussed in a modelling study by M. Eikerling [41].

The trend in Figure 7a,b also shows that this increase in $R_{m t}$ can become a relevant total for cell performance at current densities above $0.5 \mathrm{~A} \mathrm{~cm}^{-2}$, as it approaches the values for charge transfer and high frequency resistance, finally constituting $\sim 1 / 3$ of the cell's resistance in the negative impedance plane above $0.6 \mathrm{~A} \mathrm{~cm}^{-2}$.

The physical nature of the PLFI signal can be discussed in theory and the most plausible assumptions can be made based on the explanation provided by D. Klotz [5]. One explanation is simply put: It is a measurement artefact stemming from joule heating by the current change during EIS. A remedy would be provided by an experimental setup with highly efficient cooling channels, able to completely remove the generated heat in a time frame of at least $<5 \mathrm{~s}$ to keep the temperature constant during measurement in the frequency range of $0.2-0.01 \mathrm{~Hz}$. This is not a common feature in single-cell testing hardware. In such a case, the negative capacitance and resistance can be used as an empirical correction factor to account for this measurement artefact, when simulating the transport related resistance directly adjacent. Another possible explanation could be the two-step nature of the oxygen reduction reaction through an intermediate state [5,15]. It is possible that the time constant of reaction one (oxygen hydrogen peroxide) is much larger than the time constant of reaction two (hydrogen peroxide water). Apart from the physical nature of the negative $\mathrm{R}_{\text {intermediate }}-\mathrm{CPE}_{\text {intermediate, }}$ the additional degrees of freedom introduced by this circuit element and its ability to mathematically represent the PLFI loop (in contrast to a model without it) lead to a higher precision of determination for the other well-defined circuit elements. The second and most commonly cited reason for the appearance of the PLFI loop is the resistance introduced by the oxidation of an intermediate product, namely $\mathrm{PtO} / \mathrm{PtOH}$ or $\mathrm{PtO}_{2} \mathrm{H}[5,15]$.

\section{Conclusions}

An equivalent circuit model for the description of the complete impedance spectrum was developed and used to study the influence of catalyst layer thickness on the resistance contributions of membrane electrode assemblies for PEMFC. The new model was created by combining basic known equivalent circuit models that have proved to be incomplete due to their inability to describe EIS signals over the whole spectrum of $10^{4}-10^{-2} \mathrm{~Hz}$ that is typically used in measurements. The upgraded model is able to simultaneously describe low-frequency features occurring in the positive impedance plane and the classical semi-circular features in the negative impedance plane. This addition of elements leads to an improvement of the model fit and hence leads to a more precise determination of the well-defined physical elements $R_{\mathrm{ct}, \mathrm{c}}$ and $\mathrm{R}_{\mathrm{mt}}$.

The developed model was used in an electrode-design study, to optimize the layer thickness of the cathode-catalyst layer. It was shown that significant increases in diffusionrelated resistance can result from a higher catalyst-layer thickness. $R_{m t}$ increased when the catalyst layer's thickness increased from approx. 5 to $12 \mu \mathrm{m}$ :

- by $264 \%$ for the catalyst with the same structure, yet a thicker layer by doubling the Pt-loading (MEA 40/0.25 vs. MEA 40/0.125).

- by $67 \%$ for the catalyst layer using a catalyst with higher and more uniform platinum distribution (MEA20/0.125 vs. MEA 40/0.125) and lower I/C ratio (0.6 vs. 0.8).

At the same time, the membrane resistance decreased slightly, by $9 \%$, for MEA $40 / 0.250$, and by $17 \%$, for MEA 20/0.125, as compared to MEA 40/0.125. These effects on the resistance contributions were attributed to the higher degree of water retention in the catalyst layers and membrane with increasing catalyst layer thickness. 
Supplementary Materials: The following are available online at https:/ / www.mdpi.com/article/10 $.3390 /$ en14217299/s1, Figure S1: Experimental EIS data for every studied MEA recorded at 0.1 (a), 0.2 (b), 0.3 (c) and 0.4 (d) $\mathrm{A} \mathrm{cm}^{-2}$, Figure S2: Experimental EIS data recorded at 0.5, 0.6 and $0.7 \mathrm{~A} \mathrm{~cm}^{-2}$ of MEA 40/0.250, Figure S3: Linear Kramers-Kronig Analysis (red line) of the experimental data (black circles) at an operating point of $0.4 \mathrm{~A} \mathrm{~cm}^{-2}$ for (a) MEA 20/0.125, (b) MEA 40/0.125 and (b) MEA 40/0.25. On the left the Nyquist Plot is shown. At the top right the two diagrams show the Bode plot and the fitted lin-KK model. At the bottom right the real and imaginary residuals are presented, Figure S4: Linear Kramers-Kronig Analysis (red line) of the reconstructed data (ZHIT Algorithm is used; black circles) at an operating point of $0.4 \mathrm{~A} \mathrm{~cm}^{-2}$ for (a) MEA 20/0.125, (b) MEA 40/0.125 and (b) MEA 40/0.25. On the left the Nyquist Plot is shown. At the top right the two diagrams show the Bode plot and the fitted lin-KK model. At the bottom right the real and imaginary residuals are presented, Figure S5: Residuals at $0.4 \mathrm{~A} \mathrm{~cm}^{-2}$ of $\mathrm{Zr}$ (a) and $\mathrm{Zi} \mathrm{(b)} \mathrm{Model}$ 1 compared to ZHIT reconstructed data. The Frequency range was selected to better show the frequency range of interest. The highest residuals were found in the low frequency range, Figure S6: Residuals at $0.4 \mathrm{~A} \mathrm{~cm}^{-2}$ of $\mathrm{Zr}(\mathrm{a})$ and $\mathrm{Zi}$ (b) Model 2 compared to ZHIT reconstructed data. The Frequency range was selected to better show the frequency range of interest. The highest residuals were found in the low frequency range, Figure S7: Comparison of Model 2 resistance calculation when using raw data vs. ZHIT reconstructed data. No significant change in numerical values can be determined in neither $\mathrm{Rmt}$ nor $\mathrm{R}_{\mathrm{Ch}, \mathrm{C}}$.

Author Contributions: Conceptualization, M.G. (Maximilian Grandi) and K.M.; methodology, M.G. (Maximilian Grandi), K.M., M.G. (Matija Gatalo), G.K., F.R.-Z., B.M., V.H. and M.G. (Miran Gaberšček); validation, V.H. and M.G. (Miran Gaberšček); formal analysis, M.G. (Maximilian Grandi), K.M., M.G. (Matija Gatalo), B.M.; investigation, M.G. (Maximilian Grandi), K.M., M.G. (Matija Gatalo) G.K., F.R.-Z. and B.M.; resources, V.H. and M.G. (Miran Gaberšček); data curation, M.G. (Maximilian Grandi) and K.M.; writing, M.G. (Maximilian Grandi) and K.M.; writing-review and editing, V.H., M.G. (Miran Gaberšček), M.G. (Maximilian Grandi), K.M. and M.G. (Matija Gatalo); visualization, M.G. (Maximilian Grandi), K.M., M.G. (Matija Gatalo); supervision, V.H. and M.G. (Miran Gaberšček); project administration, V.H. and M.G. (Miran Gaberšček); funding acquisition, V.H., M.G. (Miran Gaberšček), M.G. (Maximilian Grandi), K.M. and M.G. (Matija Gatalo). All authors have read and agreed to the published version of the manuscript.

Funding: This research was funded by the "Zukunftsfond Steiermark", grant number PN 1312, by the Austrian Research Promotion Agency (FFG), grant number FFG 884368 and by Austria's Agency for Education and Internationalization (OeAD), grant number SI 11/2018. The open access publishing was funded by Graz University of Technology".

Institutional Review Board Statement: Not applicable.

Informed Consent Statement: Not applicable.

Acknowledgments: The authors would like to thank Brigitte Hammer and Bettina Koch for their diligent and reliable work in the secretariat of the Institute of Chemical Engineering and Environmental Technology. Special thanks are given to our family and friends for all the patience and support provided during our research. Open Access Funding by the Graz University of Technology is kindly acknowledged.

Conflicts of Interest: The authors declare no conflict of interest. The funders had no role in the design of the study; in the collection, analyses, or interpretation of data; in the writing of the manuscript, or in the decision to publish the results.

\section{References}

1. Cullen, A.D.; Neyerlin, K.C.; Ahluwalia, R.K.; Mukundan, R.; More, K.L.; Borup, R.L.; Weber, A.Z.; Myers, D.J.; Kusoglu, A. New roads and challenges for fuel cells in heavy-duty transportation. Nat. Energy 2021, 6, 462-474. [CrossRef]

2. Gittleman, C.S.; Kongkanand, A.; Masten, D.; Gu, W. Materials research and development focus areas for low cost automotive proton-exchange membrane fuel cells. Curr. Opin. Electrochem. 2019, 18, 81-89. [CrossRef]

3. Katsounaros, I.; Cherevko, S.; Zeradjanin, A.R.; Mayrhofer, K.J.J. Oxygen Electrochemistry as a Cornerstone for Sustainable Energy Conversion. Angew. Chem. Int. Ed. 2014, 53, 102-121. [CrossRef]

4. Kongkanand, A.; Mathias, M.F. The Priority and Challenge of High-Power Performance of Low-Platinum Proton-Exchange Membrane Fuel Cells. J. Phys. Chem. Lett. 2016, 7, 1127-1137. [CrossRef] 
5. Klotz, D. Negative capacitance or inductive loop?-A general assessment of a common low frequency impedance feature. Electrochem. Commun. 2019, 98, 58-62. [CrossRef]

6. Orazem, M.E.; Roy, S.K. Deterministic Impedance Models for Interpretation of Low-Frequency Inductive Loops in PEM Fuel Cells. ECS Trans. 2019, 3, 1031-1040. [CrossRef]

7. Wagner, N.; Kaz, T.; Friedrich, K.A. Investigation of electrode composition of polymer fuel cells by electrochemical impedance spectroscopy. Electrochim. Acta 2008, 53, 7475-7482. [CrossRef]

8. Wagner, N.; Gülzow, E. Change of electrochemical impedance spectra (EIS) with time during CO-poisoning of the Pt-anode in a membrane fuel cell. J. Power Sources 2004, 127, 341-347. [CrossRef]

9. Kumar, A.; Su, H.C.; Chen, Y.S.; Arpornwichanop, A. Effect of catalyst layer with zeolite on the performance of a proton exchange membrane fuel cell operated under low-humidity conditions. Int. J. Hydrogen Energy 2021, 46, 15878-15886. [CrossRef]

10. Page, S.C.; Anbuky, A.H.; Krumdieck, S.P.; Brouwer, J. Test method and equivalent circuit modeling of a PEM fuel cell in a passive state. IEEE Trans. Energy Convers. 2007, 22, 764-773. [CrossRef]

11. Schulze, M.; Wagner, N.; Kaz, T.; Friedrich, K.A. Combined electrochemical and surface analysis investigation of degradation processes in polymer electrolyte membrane fuel cells. Electrochim. Acta 2007, 52, 2328-2336. [CrossRef]

12. Pivac, I.; Barbir, F. Inductive phenomena at low frequencies in impedance spectra of proton exchange membrane fuel cells-A review. J. Power Sources 2016, 326, 112-119. [CrossRef]

13. Halvorsen, I.J.; Pivac, I.; Bezmalinović, D.; Barbir, F.; Zenith, F. Electrochemical low-frequency impedance spectroscopy algorithm for diagnostics of PEM fuel cell degradation. Int. J. Hydrogen Energy 2020, 45, 1325-1334. [CrossRef]

14. Makharia, R.; Mathias, M.F.; Baker, D.R. Measurement of Catalyst Layer Electrolyte Resistance in PEFCs Using Electrochemical Impedance Spectroscopy. J. Electrochem. Soc. 2005, 152, A970. [CrossRef]

15. Roy, S.K.; Orazem, M.E. Tribollet, Interpretation of Low-Frequency Inductive Loops in PEM Fuel Cells. J. Electrochem. Soc. 2007, 154, B1378. [CrossRef]

16. Gomadam, P.M.; Weidner, J.W. Analysis of electrochemical impedance spectroscopy in proton exchange membrane fuel cells. Int. J. Energy Res. 2005, 29, 1133-1151. [CrossRef]

17. Yuan, X.; Wang, H.; Sun, J.C.; Zhang, J. AC impedance technique in PEM fuel cell diagnosis-A review. Int. J. Hydrogen Energy 2007, 32, 4365-4380. [CrossRef]

18. Kuhn, H.; Andreaus, B.; Wokaun, A.; Scherer, G.G. Electrochemical impedance spectroscopy applied to polymer electrolyte fuel cells with a pseudo reference electrode arrangement. Electrochim. Acta 2006, 51, 1622-1628. [CrossRef]

19. Springer, T.E.; Zawodzinski, T.A.; Wilson, M.S.; Gottesfeld, S. Characterization of Polymer Electrolyte Fuel Cells Using AC Impedance Spectroscopy. J. Electrochem. Soc. 1996, 143, 587-599. [CrossRef]

20. Hombrados, A.G.; González, L.; Rubio, M.A.; Agila, W.; Villanueva, E.; Guinea, D.; Chinarro, E.; Moreno, B.; Jurado, J.R. Symmetrical electrode mode for PEMFC characterisation using impedance spectroscopy. J. Power Sources 2005, 151, 25-31. [CrossRef]

21. Breitwieser, M.; Klose, C.; Klingele, M.; Hartmann, A.; Erben, J.; Cho, H.; Kerres, J.; Zengerle, R.; Thiele, S. Simple fabrication of $12 \mu \mathrm{m}$ thin nanocomposite fuel cell membranes by direct electrospinning and printing. J. Power Sources 2017, 337, 137-144. [CrossRef]

22. Pivac, I.; Bezmalinović, D.; Barbir, F. Catalyst degradation diagnostics of proton exchange membrane fuel cells using electrochemical impedance spectroscopy. Int. J. Hydrogen Energy 2018, 43, 13512-13520. [CrossRef]

23. Baricci, A.; Bonanomi, M.; Yu, H.; Guetaz, L.; Maric, R.; Casalegno, A. Modelling analysis of low platinum polymer fuel cell degradation under voltage cycling: Gradient catalyst layers with improved durability. J. Power Sources 2018, 405, 89-100. [CrossRef]

24. Shrivastava, N.K. Effect of cell compression on the performance of a non-hot-pressed MEA for PEMFC. Int. J. Hydrogen Energy 2019, 44, 370-385. [CrossRef]

25. Dhirde, A.M.; Dale, N.V.; Salehfar, H.; Mann, M.D.; Han, T.H. Equivalent electric circuit modeling and performance analysis of a PEM fuel cell stack using impedance spectroscopy. IEEE Trans. Energ. Convers. 2010, 25, 778-786. [CrossRef]

26. Zamboni, W.; Petrone, G.; Spagnuolo, G.; Beretta, D. An evolutionary computation approach for the online/on-board identification of PEM fuel cell impedance parameters with a diagnostic perspective. Energies 2019, 12, 4374. [CrossRef]

27. Sung, Y.E.; Jang, J.H.; Lee, S.Y.; Lee, B.S.; Kim, H.J.; Henkensmeier, D.; Yoo, S.J.; Kim, J.Y.; Han, J.; Park, H.S.; et al. Effect of Catalyst Layer Ionomer Content on Performance of Intermediate Temperature Proton Exchange Membrane Fuel Cells (IT-PEMFCs) under Reduced Humidity Conditions. Electrochim. Acta 2017, 224, 228-234. [CrossRef]

28. Kim, K.H.; Lee, K.Y.; Lee, S.Y.; Cho, E.; Lim, T.H.; Kim, H.J.; Yoon, S.P.; Kim, S.H.; Lim, T.W.; Jang, J.H. The effects of relative humidity on the performances of PEMFC MEAs with various Nafion ${ }^{\circledR}$ ionomer contents. Int. J. Hydrogen Energy 2010, 35, 13104-13110. [CrossRef]

29. Lee, H.; Park, J.; Kim, D.; Lee, T. A study on the characteristics of the diffusion layer thickness and porosity of the PEMFC. J. Power Sources 2004, 131, 200-206. [CrossRef]

30. Owejan, J.P.; Owejan, J.E.; Gu, W. Impact of Platinum Loading and Catalyst Layer Structure on PEMFC Performance. J. Electrochem. Soc. 2013, 160, F824. [CrossRef] 
31. Xiong, Y.; Yang, Y.; Disalvo, F.J.; Abruña, D.H. Pt-Decorated Composition-Tunable Pd-Fe@Pd/C Core-Shell Nanoparticles with Enhanced Electrocatalytic Activity toward the Oxygen Reduction Reaction. J. Am. Chem. Soc. 2018, 140, 7248-7255. [CrossRef] [PubMed]

32. Lu, B.A.; Sheng, T.; Tian, N.; Zhang, Z.C.; Xiao, C.; Cao, Z.M.; Ma, H.B.; Zhou, Z.Y.; Sun, S.G. Octahedral PtCu alloy nanocrystals with high performance for oxygen reduction reaction and their enhanced stability by trace Au. Nano Energy 2017, 33, 65-71. [CrossRef]

33. Chung, H.T.; Cullen, D.A.; Higgins, D.; Sneed, B.T.; Holby, E.F.; More, K.L.; Zelenay, P. Direct atomic-level insight into the active sites of a high-performance PGM-free ORR catalyst. Science 2017, 357, 479-484. [CrossRef] [PubMed]

34. Jiang, K.; Zhao, D.; Guo, S.; Zhang, X.; Zhu, X.; Guo, J. Efficient oxygen reduction catalysis by subnanometer Pt alloy nanowires Efficient oxygen reduction catalysis by subnanometer Pt alloy nanowires. Sci. Adv. 2017, 3, 2-9. [CrossRef]

35. Banham, D.; Ye, S. Current Status and Future Development of Catalyst Materials and Catalyst Layers for Proton Exchange Membrane Fuel Cells: An Industrial Perspective. ACS Energy Lett. 2017, 2, 629-638. [CrossRef]

36. Kodama, K.; Nagai, T.; Kuwaki, A.; Jinnouchi, R.; Morimoto, Y. Challenges in applying highly active Pt-based nanostructured catalysts for oxygen reduction reactions to fuel cell vehicles. Nat. Nanotechnol. 2021, 16, 140-147. [CrossRef]

37. Pan, L.; Ott, S.; Dionigi, F.; Strasser, P. Current challenges related to the deployment of shape-controlled Pt alloy oxygen reduction reaction nanocatalysts into low Pt-loaded cathode layers of proton exchange membrane fuel cells. Curr. Opin. Electrochem. 2019, 18, 61-71. [CrossRef]

38. Lee, J.; Chevalier, S.; Banerjee, R.; Antonacci, P.; Ge, N.; Yip, R.; Kotaka, T.; Tabuchi, Y.; Bazylak, A. Electrochimica Acta Investigating the effects of gas diffusion layer substrate thickness on polymer electrolyte membrane fuel cell performance via synchrotron X-ray radiography. Electrochim. Acta 2017, 236, 161-170. [CrossRef]

39. Mauger, S.A.; Wang, M.; Cetinbas, F.C.; Dzara, M.J.; Park, J.; Myers, D.J.; Ahluwalia, R.K.; Pylypenko, S.; Hu, L.; Litster, S.; et al. Development of high-performance roll-to-roll-coated gas-diffusion-electrode-based fuel cells. J. Power Sources 2021, 506, 230039. [CrossRef]

40. Du, S.; Li, W.; Wu, H.; Chuang, P.Y.A.; Pan, M.; Sui, P.C. Effects of ionomer and dispersion methods on rheological behavior of proton exchange membrane fuel cell catalyst layer ink. Int. J. Hydrogen Energy 2020, 45, 29430-29441. [CrossRef]

41. Eikerling, M. Water Management in Cathode Catalyst Layers of PEM Fuel Cells: A Structure-Based Model PEM Fuel Cells. J. Electrochem. Soc. J. Electrochem. Soc. 2006, 153, E58. [CrossRef]

42. Schulze, M.; Gülzow, E.; Steinhilber, G. Activation of nickel-anodes for alkaline fuel cells. Appl. Surf. Sci. 2001, 179, 251-256. [CrossRef]

43. Bard, A.J. Electrochemical Methods: Fundamentals and Applications; Bard, A.J., Faulkner, L.R., Eds.; Wiley: New York, NY, USA, 1980.

44. Mayrhofer, K.J.J.; Strmčnik, D.; Blizanac, B.B.; Stamenković, V.R.; Arenz, M.; Marković, N.M. Measurement of Oxygen Reduction Activities via the Rotating Disc Electrode Method: From Pt Model Surfaces to Carbon-supported High Surface Area Catalysts. Electrochim. Acta 2008, 53, 3181-3188. [CrossRef]

45. Mamlouk, M.; Scott, K. Analysis of high temperature polymer electrolyte membrane fuel cell electrodes using electrochemical impedance spectroscopy. Electrochim. Acta 2011, 56, 5493-5512. [CrossRef]

46. Lechartier, E.; Laffly, E.; Péra, M.C.; Gouriveau, R.; Hissel, D.; Zerhouni, N. Proton exchange membrane fuel cell behavioral model suitable for prognostics. Int. J. Hydrogen Energy 2015, 40, 8384-8397. [CrossRef]

47. Hsieh, S.S.; Yang, S.H.; Feng, C.L. Characterization of the operational parameters of a H2/air micro PEMFC with different flow fields by impedance spectroscopy. J. Power Sources 2006, 162, 262-270. [CrossRef]

48. Rubio, M.A.; Urquia, A.; Dormido, S. Diagnosis of PEM fuel cells through current interruption. J. Power Sources 2007, 171, 670-677. [CrossRef]

49. Rubio, M.A.; Urquia, A.; Kuhn, R.; Dormido, S. Electrochemical parameter estimation in operating proton exchange membrane fuel cells. J. Power Sources 2008, 183, 118-125. [CrossRef] 